\title{
SAFETY AND EFFICACY OF MANUAL SMALL INCISION CATARACT SURGERY IN A RURAL HEALTH CARE SETTING IN TAMILNADU
}

\author{
V. Sridevi ${ }^{1}$, P. Ramya ${ }^{2}$
}

${ }^{1}$ Associate Professor, Department of Ophthalmology, Rajah Muthiah Medical College and Hospital, Annamalai Nagar, Chidambaram. ${ }^{2}$ Postgraduate Student, Department of Ophthalmology, Rajah Muthiah Medical College and Hospital, Annamalai Nagar, Chidambaram.

\section{ABSTRACT}

\section{BACKGROUND}

MSICS demands skill and patience from the cataract surgeon. It is a safe, effective and economical alternative to competing techniques and can be the answer to tackle the large backlog of blindness due to cataract. Cataract is defined as any opacity of lens and its capsule. It is the commonest cause of avoidable blindness in India (50\% - 80\%). Cataract surgery has been there since $28^{\text {th }}$ century. It is treated by various methods. It has undergone great refinement in recent years from age old couching to sutureless surgery and phacoemulsification.

\section{MATERIALS AND METHODS}

This prospective case series is done on 50 patients undergoing manual SICS in Department of Ophthalmology, Rajah Muthiah Medical College and Hospital over a period from October 2015 to March 2016. All patients who were fit to undergo manual small incision cataract surgery during the above-mentioned period were included in the present case series.

\section{RESULTS}

This prospective case series which involved 50 patients and conducted between October 2015 and March 2016 revealed the mean age of presentation was 58 years. The commonly affected age group was $51-60$ years (32\%). Female patients constituted $60 \%$ of the case series population. Left eye was involved in $60 \%$ of the cases. Most common intraoperative complication was difficulty in delivering the nucleus into anterior chamber, 8\%. Least common complications were PC rent, primary PCO, Zonular dehiscence and premature entry each accounting for $2 \%$. Most common postoperative complication was iritis $14 \%$ and least common complication was corneal oedema $2 \%$.

\section{CONCLUSION}

Manual Small Incision Cataract Surgery is small incisioned, sutureless, self-sealing and safe cataract surgery. Manual SICS has a less steep learning curve than Phacoemulsification. Manual SICS is cost effective when compared to Phacoemulsification and is the choice of surgery in high volume centres and developing countries. Manual SICS has a lower complication rates as compared to conventional ECCE. Manual SICS has similar intraoperative and postoperative complication rate as compared to Phacoemulsification.

\section{KEYWORDS}

Cataract Surgery, Intraoperative and Postoperative Complications, MSICS.

HOW TO CITE THIS ARTICLE: Sridevi V, Ramya P. Safety and efficacy of manual small incision cataract surgery in a rural health care setting in Tamilnadu. J. Evolution Med. Dent. Sci. 2017;6(64):4676-4679, DOI: 10.14260/Jemds/2017/1011

\section{BACKGROUND}

Cataract is defined as any opacity of lens and its capsule. It is the commonest cause of avoidable blindness in India (50\% $80 \%$ ). Cataract surgery has been there since $28^{\text {th }}$ century. It is treated by various methods. It has undergone great refinement in recent years from age old couching to sutureless surgery and phacoemulsification. MSICS is cost effective and has the advantages of small sutureless surgery without the high complications of a budding phaco-surgeon.

Financial or Other, Competing Interest: None.

Submission 14-07-2017, Peer Review 31-07-2017,

Acceptance 04-08-2017, Published 10-08-2017.

Corresponding Author:

V. Sridevi,

Associate Professor,

Department of Ophthalmology,

Rajah Muthiah Medical College \& Hospital,

Annamalai Nagar,

Chidambaram-608002.

E-mail: srithithi@gmail.com

DOI: $10.14260 /$ jemds/2017/1011
Modern cataract surgery aims to achieve a better unaided visual acuity with rapid post-surgical recovery and minimal surgery related complications. Early visual rehabilitation, better unaided visual acuity and surgical safety can be achieved in a great measure by reducing the incision size.

Manual small incision cataract surgery offers similar advantages with the merits of wider applicability, better safety, a shorter learning curve and lower cost. Phacoemulsification requires expensive instrumentation which may not be available at all centres, whereas manual SICS requires only a minimum addition to the standard cataract surgery instrument armamentarium. Case selection is very important for an average surgeon doing phacoemulsification, and duration of surgery and incidence of intraoperative complications varies with the nucleus density. Certain cataracts like hypermature, Morgagnian or traumatic cataracts are difficult to handle with phacoemulsification. Manual SICS can be performed in almost all types of cataracts and time spent on nucleus delivery does not vary with the cataract. 
Case selection is very important for an average surgeon doing phacoemulsification, and duration of surgery and incidence of intraoperative complications varies with the nucleus density. Certain cataracts like hypermature, Morgagnian or traumatic cataracts are difficult to handle with phacoemulsification. Manual SICS can be performed in almost all types of cataracts and time spent on nucleus delivery does not vary with the cataract. The objective of the present case series is to study intraoperative and postoperative complications following Manual Small Incision Cataract Surgery done at Rajah Muthiah Medical College Hospital.

\section{MATERIALS AND METHODS}

This is a prospective case series of 50 patients assigned to undergo MSICS. From October 2015 to September 2016 at Department of Ophthalmology, Rajah Muthiah Medical College and Hospital. The surgeries were done by different consultants and residents in the Department. Routine investigations like HIV, HBsAg, RBS, urine routine and general examination were done for all patients. Patients received topical antibiotic eye drop one day prior to surgery. Tropicamide and phenylephrine eye drops were instilled every 15 minutes starting 2 hours prior to surgery.

\section{Inclusion Criteria}

1. Senile Mature Cortical Cataract.

2. Senile Immature Cortical Cataract.

3. Posterior Subcapsular Cataract.

4. Nuclear Sclerosis Grade- III and IV.

\section{Exclusion Criteria}

\section{Subluxated Cataract}

Preoperative Assessment of a Patient for SICS.

A good endothelial count, well dilating pupil, intact zonular apparatus and ocular tone are required to perform this procedure safely.

Assessment of the cornea with slit lamp under high magnification should be done to rule out pathologies with a low endothelial count (Glaucoma, Fuchs' dystrophy, etc.). Where possible, endothelial counts should be obtained. Evidence of chronic iritis and keratitic precipitates should be carefully looked for.

Iris pupil examination under mesopic light conditions should be done to see for evidence of posterior synechiae, pigment on the lens and pupillary abnormalities. Pupil examination should also be done after dilatation to know the status of the pupil (whether dilating satisfactorily or not) and the lens (grading of the cataract, zonular status).

Posterior segment evaluation gives us important information about the visual prognosis after surgery.

IOP measurement is a must before SICS.

Certain absolute contraindications to SICS include Fuchs' dystrophy, microphthalmos, congenital anomalies, zonular dialysis and lens subluxation.

\section{RESULTS}

In this case series, $2 / 3^{\text {rd }}$ of patients were females $(60 \%)$ and $1 / 3^{\text {rd }}$ were males $(40 \%)$. The most commonly affected age group was between 50 and 60 years. Left eye involvement was more common than right eye in our case series. The least common on table complications noted were posterior capsule rent $2 \%$, zonular dehiscence $2 \%$ followed by primary PCO $2 \%$. Difficulty in delivering the nucleus $8 \%$ was considered to be the most common on table complication. The others were intraoperative miosis $6 \%$ and positive pressure $4 \%$.

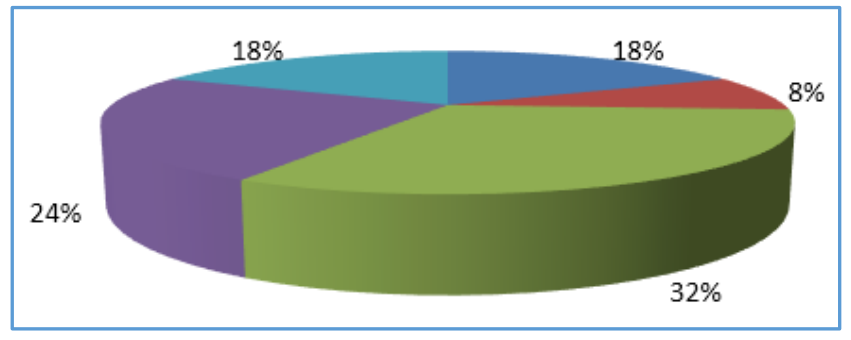

Figure 1. Age Distribution

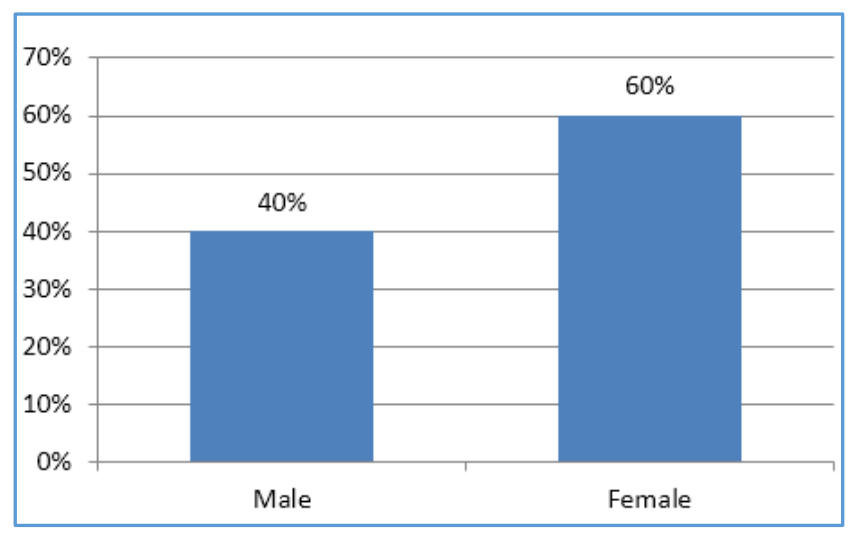

Figure 2. Sex Distribution

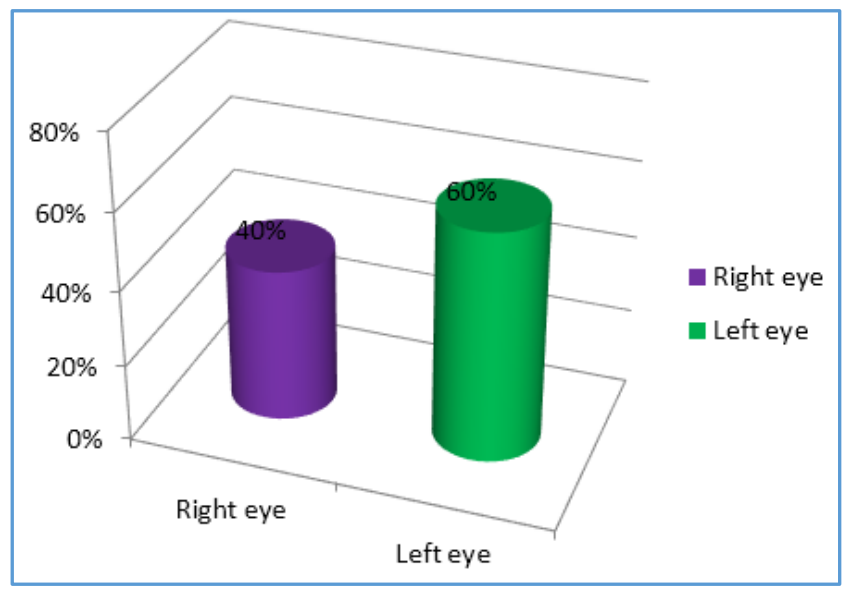

Figure 3. Laterality

Iritis (14\%) was the first encountered postoperative complication observed on Day 1 followed by striate keratopathy $(10 \%)$. The others were raised IOP in $8 \%$ and retained lens material was seen in $6 \%$. Corneal oedema was seen in only $2 \%$ of cases.

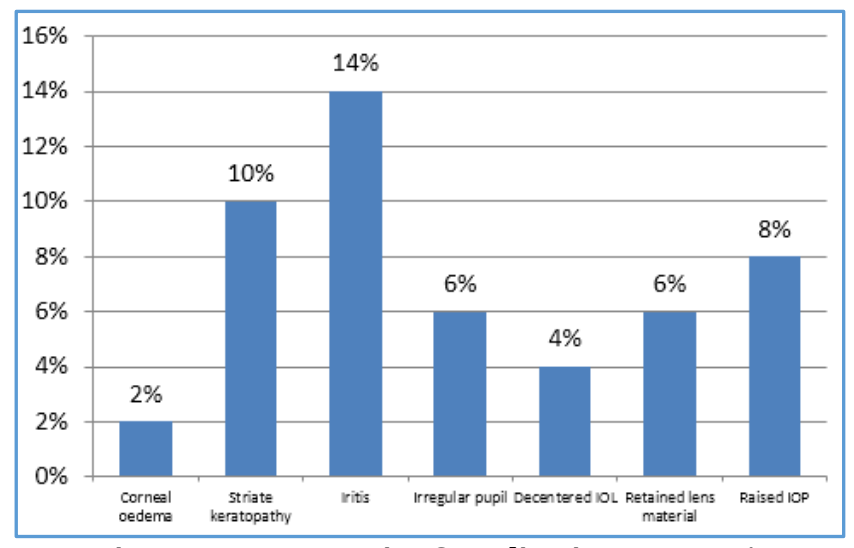

Figure 4. Postoperative Complications on Day 1 
Postoperative iritis in the first week after surgery was observed in $10 \%$ of cases. Optic capture, retained lens matter and raised IOP was noted in $2 \%$ of cases in this case series.

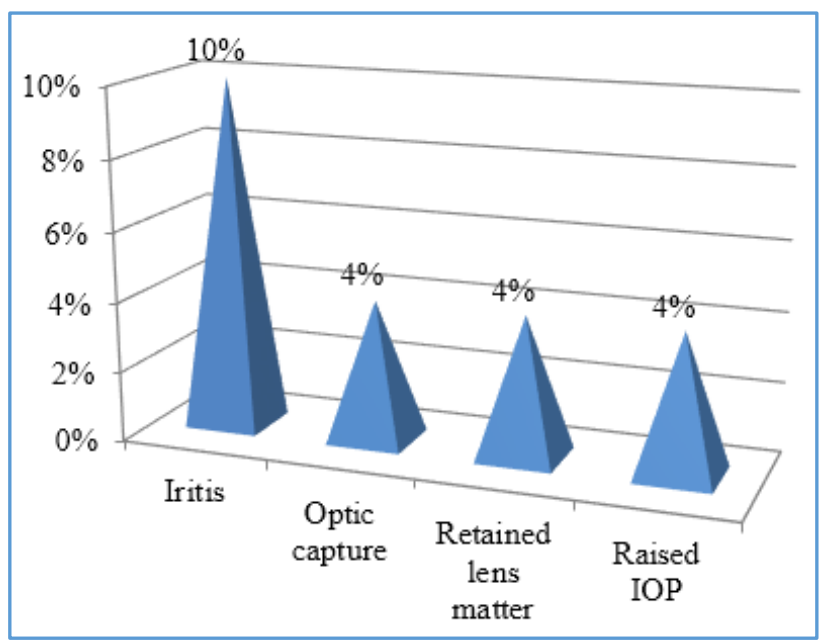

Figure 5. Postoperative Complications on $1^{\text {st }}$ Week

In our case series iritis, retained lens matter and optic capture were observed in 2 cases each at fourth week of followup.

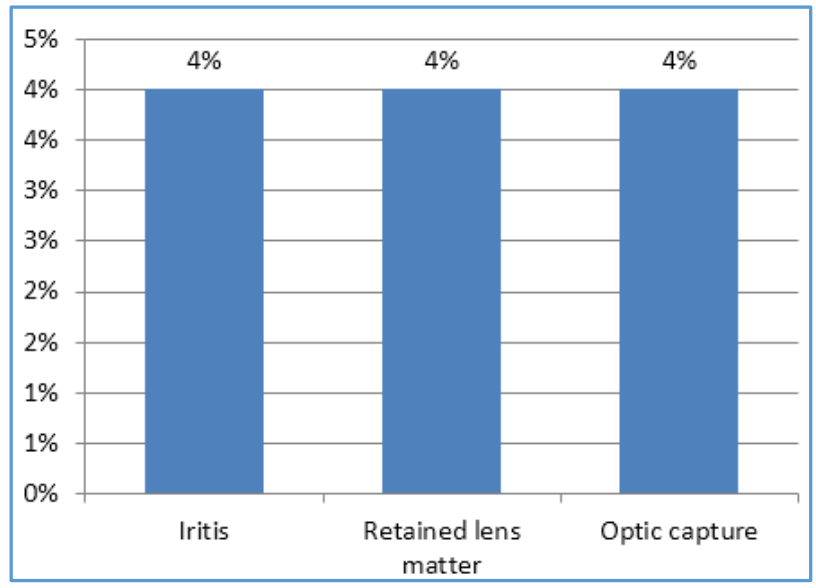

Figure 6. Postoperative Complications on $4^{\text {th }}$ Week

The postoperative iritis rate had declined to $2 \%$ at the end of $6^{\text {th }}$ week. Optic capture and retained lens matter persisted in $2 \%$ of the cases.

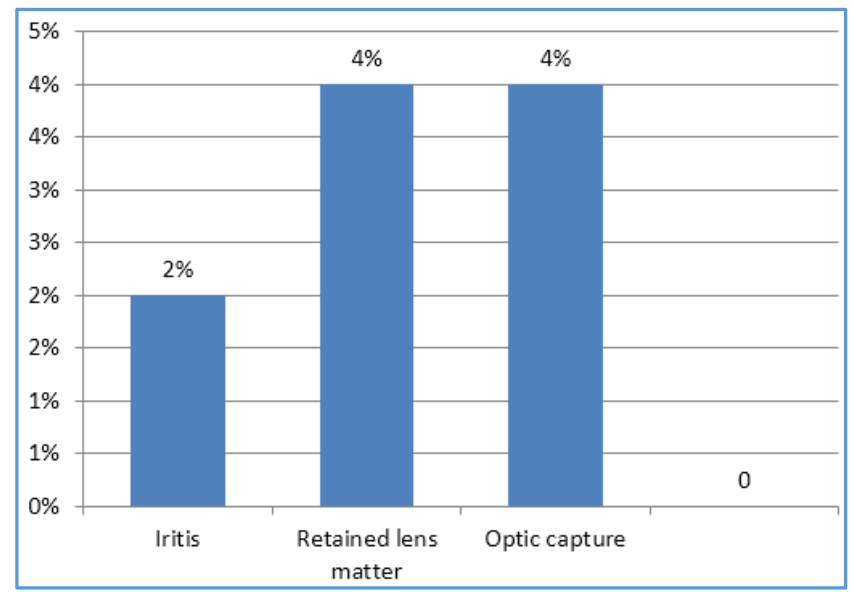

Figure 7. Postoperative Complications on $6^{\text {th }}$ Week

\section{DISCUSSION}

In our case series of 50 patients, the mean age of patients was 58 years. There were 20 male and 30 female patients. Out of 20 male patients, 3 patients were in the age group of $<40$ yrs., 2 patients were in the age group of $41-50$ yrs., 5 patients were in the age group of $51-60$ yrs., 8 patients were in the age group of $61-70$ yrs., 2 patients were in the age group of $71-80$ yrs. Out of 30 female patients, 6 patients were in the age group of $<40$ yrs., 2 patients were in the age group of $41-50$ yrs., 11 patients were in the age group of 51 -60 yrs., 4 patients were in the age group of $61-70$ yrs. and 7 patients were in the age group of $71-80 \mathrm{yrs}$.

The number of patients operated for the right eye accounted for $40 \%$ and left eye accounted for the rest, i.e. $60 \%$.

All the patients under study were examined postoperatively on the first day, first week, fourth week and sixth week.

Intraoperative miosis was observed in $6 \%$ as compared to Venkatesh et $\mathrm{al}^{1}$ case series; it was noted in $4 \%$ in our case series.

Intraoperative PC rent was seen in $2 \%$ in our case series as compared to $1.9 \%$ in $\mathrm{R}$ Venkatesh et al, $21.4 \%$ in $\mathrm{R}$ Venkatesh et $\mathrm{al}^{3}, 0.5 \%$ in A Haripriya et $\mathrm{al}^{4}$ and $2.4 \%$ in Mrunal et al. ${ }^{5}$ In Khanna et $\mathrm{al}^{6}$ case series PC rent was reported in 6.9\%, whereas it was $6.1 \%$ in Signes-Soler et al case series, ${ }^{7} 6.7 \%$ in Gogate et $\mathrm{al}^{8}$ and $5 \%$ in YasirIqbal et al ${ }^{9}$ case series.

Iridodialysis was reported in $1 \%$ in Venkatesh et al, ${ }^{1}$ $0.03 \%$ in A Haripriya et $\mathrm{al}^{4}$ case series, $1.02 \%$ in Signes-Soler et $\mathrm{al}^{7}$ case series, $0.5 \%$ in Gogate et $\mathrm{al}^{8}$ case series and $0.6 \%$ in Yasirlqbal et $\mathrm{al}^{9}$ case series.

Zonular dehiscence was seen in $2 \%$ of the patients in our case series, whereas it was seen in $0.5 \%$ of cases in $R$ Venkatesh et $\mathrm{al}^{3}$ case series, $0.09 \%$ in A Haripriya et $\mathrm{al}^{4}$ case series and $0.8 \%$ in Mrunal et $\mathrm{al}^{5}$ case series.

Other intraoperative complications reported in our case series are difficulty in delivering the nucleus (8\%), which was the most common complication. Intraoperative miosis (6\%), difficulty in dialing the nucleus into AC (4\%), positive pressure (4\%) and endothelial touch (4\%).

In our case series, the most frequently encountered postoperative complication was iritis which was seen in $14 \%$ of the cases. Venkatesh et al $^{1}$ case series reported iritis in $9 \%$, $\mathrm{R}$ Venkatesh et $\mathrm{al}^{2}$ case series reported iritis in 8.8\%, 5.9\% cases had iritis in Venkatesh et al ${ }^{10}$ case series, $2.51 \%$ had iritis in Gogate et $\mathrm{al}^{8}$ case series and $3.3 \%$ had iritis in Yasirlqbal et al $^{9}$ case series.

$0.04 \%$ of cases had endophthalmitis in A Haripriya et $\mathrm{al}^{4}$ case series, but none was reported in our case series.

Corneal oedema $2 \%$ was much lesser when compared to other studies.

Retained lens matter was seen in $6 \%$ in our case series which was higher compared to $\mathrm{R}$ Venkatesh et $\mathrm{al}^{3}$ case series $0.2 \%$ and Signes-Soler et al $^{7}$ case series $1.02 \%$.

\section{CONCLUSION}

This prospective case series, which involved 50 patients revealed that the mean age of presentation was 58 years. The commonly affected age group was 51 - 60 years (32\%). 
Female patients constituted $60 \%$ of the study population. Left eye was involved in $60 \%$ of the cases. Most common intraoperative complication was difficulty in delivering the nucleus into anterior chamber, $8 \%$. Least common complications were PC rent, Primary PCO, Zonular dehiscence and Premature entry each accounting for $2 \%$. Most common postoperative complication was Iritis $14 \%$ and least common complication was corneal oedema $2 \%$. Majority of patients achieved BCVA of $6 / 12$ on first post-operative day. Endophthalmitis, a dreaded complication was not observed in any of the patients in this study.

Surgically induced astigmatism following phacoemulsification with rigid IOL implantation and manual SICS have been found to be comparable; the difference between groups not reaching statistical significance in a recent large study. The cost of a foldable IOL is much higher, placing it out of the reach of many of our patients. Disadvantages of rigid IOLs of a small size are well known. A standard large optic rigid IOL can be used with ease with manual SICS. The final visual acuity has been observed to be similar after both techniques. Phacoemulsification depends upon the machine and machine failure can have serious consequences during a procedure. In SICS, however, the surgical skill and experience of the surgeon play a significant role in the results. Another advantage of manual SICS over other methods of cataract surgery is the shorter duration taken, making it particularly applicable to high volume cataract surgery. Transition to phacoemulsification is easier if one has mastered manual SICS, as familiarity of steps common to both (scleral tunnel incision, capsulorrhexis, hydroprocedures, etc.) helps reduce the incidence of complications while learning phacoemulsification.

Capsulorrhexis is mandatory for phacoemulsification, whereas manual SICS can be comfortably done with the canopener or the envelope capsulotomy skills acquired previously. Published data shows that intraoperative complications like posterior capsule rupture are more common in phacoemulsification as compared to manual SICS. Endothelial loss in phacoemulsification depends on the density of the nucleus, whereas in manual SICS the skill of the surgeon plays an important role. Overall, endothelial cell counts after surgery are comparable after phacoemulsification and manual SICS.

Due to the increasing cost of equipment for performing phacoemulsification as well as steep learning curve for the technique compared to the relative ease in learning manual SICS, together with its low economic impact on the patients, considering the results from this case series and various other case series with corroborative results, it can be safely concluded that manual SICS is the best alternative to phacoemulsification in developing countries

\section{REFERENCES}

[1] Venkatesh R, Das M, Prashanth S, et al. Manual small incision cataract surgery in eyes with white cataracts. Indian J Ophthalmol 2005;53(3):173-6.

[2] Venkatesh R, Tan CS, Singh GP, et al. Safety and efficacy of manual small incision cataract surgery for brunescent and black cataracts. Eye (Lond) 2009; 23(5):1155-7.

[3] Venkatesh R, Muralikrishnan R, Balent LC, et al. Outcomes of high volume cataract surgeries in a developing country. Br J Ophthalmol 2005;89(9): 1079-83.

[4] Haripriya A, Chang DF, Reena M, et al. Complication rates of phacoemulsification and manual smallincision cataract surgery at Aravind eye hospital. J Cataract Refract Surg 2012;38(8):1360-9.

[5] Patil MS, Balwir DN, Dua S. Case series of intraoperative complications in small incision cataract surgery, its management and visual outcome. MVP Journal of Medical Sciences 2016;3(1).

[6] Khanna RC, Kaza S, Shantha PSG, et al. Comparative outcomes of manual small incision cataract surgery and phacoemulsification performed by ophthalmology trainees in a tertiary eye care hospital in India: a retrospective cohort design. BMJ Open 2012;2(5).

[7] Signes-Soler I, Javaloy J, Munoz G, et al. Safety and efficacy of transition from Extracapsular Cataract Extraction to Manual Small Incision Cataract Surgery in Prevention of Blindness Campaigns. Middle East Afr J Opthalmol 2016;23(2):187-94.

[8] Gogate PM, Deshpande M, Wormald RP, et al. Extracapsular cataract surgery compared with manual small incision cataract surgery in community eye care setting in western India: a randomised controlled trial. Br J Ophthalmol 2003;87(6):667-72.

[9] Iqbal Y, Zia S, Mirza AUB. Intraoperative and early postoperative complications of manual sutureless cataract extraction. Journal of the College of Physicians and Surgeons Pakistan 2014;24(4):252-5.

[10] Nkanga DG, Asana UE, Etim BA, et al. Outcome of surgery in a manual small incision cataract surgery training in Calabar, Nigeria. Archives of international surgery 2015;5(2):96-100. 